Geological Society, London, Special Publications

Vital effects and beyond: a modelling perspective on developing palaeoceanographical proxy relationships in foraminifera

Richard E. Zeebe, Jelle Bijma, Bärbel Hönisch, Abhijit Sanyal, Howard J. Spero and Dieter A. Wolf-Gladrow

Geological Society, London, Special Publications 2008; v. 303; p. 45-58 doi:10.1144/SP303.4

Email alerting service

Permission request

Subscribe click here to receive free email alerts when new articles cite this article

click here to seek permission to re-use all or part of this article

click here to subscribe to Geological Society, London, Special Publications or the Lyell Collection

Notes

Downloaded by on 6 September 2008 


\title{
Vital effects and beyond: a modelling perspective on developing palaeoceanographical proxy relationships in foraminifera
}

\author{
RICHARD E. ZEEBE ${ }^{1}$, JELLE BIJMA², BÄRBEL HÖNISCH ${ }^{3,4}$, ABHIJIT SANYAL $^{4}$, \\ HOWARD J. SPERO ${ }^{5} \&$ DIETER A. WOLF-GLADROW ${ }^{2}$ \\ ${ }^{1}$ School of Ocean and Earth Science and Technology, Department of Oceanography, \\ University of Hawaii at Manoa, 1000, Pope Road, MSB 504, Honolulu, HI 96822, USA
}

(e-mail:zeebe@soest.hawaii.edu)

${ }^{2}$ Alfred Wegener Institute for Polar and Marine Research, Am Handelshafen 12, D-27570 Bremerhaven, Germany

${ }^{3}$ Marum, Bremen University, Leobener Strasse, 28359 Bremen, Germany

${ }^{4}$ Lamont-Doherty Earth Observatory of Columbia University, Geochemistry Building, 61 Route 9W, Palisades, NY, 10964, USA

${ }^{5}$ Geology Department, University of California, One Shields Avenue, Davis, CA 95616-8605, USA

\begin{abstract}
This paper mainly reviews our recent work on the biology and geochemistry of foraminifera with respect to their use as palaeoceanographic proxies. Our approach to proxy validation and development is described, primarily from a modeler's point of view. The approach is based on complementary steps in understanding the inorganic chemistry, inorganic isotope fractionation, and biological controls that determine palaeo-tracer signals in organisms used in climate reconstructions. Integration of laboratory experiments, field and culture studies, theoretical considerations and numerical modelling holds the key to the method's success. We describe effects of life-processes in foraminifera on stable carbon, oxygen, and boron isotopes as well as $\mathrm{Mg}$ incorporation into foraminiferal calcite shells. Stable boron isotopes will be used to illustrate our approach. We show that a mechanism-based understanding is often required before primary climate signals can be extracted from the geologic record because the signals can be heavily overprinted by secondary, non-climate related phenomena. Moreover, for some of the proxies, fundamental knowledge on the thermodynamic, inorganic basis is still lacking. One example is stable boron isotopes, a palaeo- $p \mathrm{H}$ proxy, for which the boron isotope fractionation between the dissolved boron compounds in seawater was not precisely known until recently. Attempts to overcome such hurdles are described and implications of our work for palaeoceanographic reconstructions are discussed.
\end{abstract}

Development and validation of palaeoceanographic proxy relationships in foraminifera have evolved rapidly over the past few years. During the early years of palaeoceanography, offsets from isotopic and elemental geochemical equilibrium that were attributed to life processes were often referred to as biological 'vital effects'. In the case of stable carbon and oxygen isotopes, the black box was opened, resulting in a precise characterization of biological effects on geochemical signals recorded in the calcite shells of foraminifera. Interspecific variations have long been recognized in the stable carbon and oxygen isotope system (for review, see Wefer \& Berger 1991; Spero 1998). However, the breakthrough in understanding inter- as well as intraspecific isotope variability came with culture experiments of live foraminifera under controlled laboratory conditions (Bijma et al. 1998; BouvierSoumagnac \& Duplessy 1985; Hemleben et al. 1985; Spero \& DeNiro 1987; Spero \& Williams 1988; Spero \& Lea 1993, 1996) as pioneered by Bé et al. (1977) and Hemleben et al. (1977).

The profound consequences of controlled culture experiments for palaeoceanographic interpretations were widely recognized in 1997, when Spero and coworkers demonstrated that the seawater carbonate chemistry significantly affects $\delta^{13} \mathrm{C}$ and $\delta^{18} \mathrm{O}$ in planktonic foraminifera (Spero et al. 1997; Bijma et al. 1999). This phenomenon has been referred to as the 'carbonate ion effect'. While palaeoceanographers had long been aware that temperature and seawater $\delta^{18} \mathrm{O}$ affect foraminiferal $\delta^{18} \mathrm{O}$ (Emiliani 1955; Shackleton 1967), another important player, the ocean's $\mathrm{CO}_{2}$ chemistry, had to be added to the 
list. As a result, $\delta^{18} \mathrm{O}$-based temperature estimates are likely too low for geologic periods in the more distant past of high atmospheric $\mathrm{CO}_{2}$ concentrations and low oceanic $p \mathrm{H}$ (Zeebe 2001; Royer et al. 2004; Bice et al. 2006).

With respect to quantitative modelling of life processes in foraminifera, a first attempt to open the 'vital effect' black box by means of a mathematical approach was provided by Spero et al. (1991). Their work outlined an abstracting concept, transforming geometry and fluxes in the living organism (Fig. 1) into mathematical equations which allowed the calculation of stable carbon isotope fractionation in a model foraminifer. But it was not until after the discovery of the carbonate ion effect that more sophisticated tools such as numerical models of the chemical microenvironment (Fig. 2) were developed to understand life processes, stable isotope fractionation, the carbonate ion effect and, prospectively, trace metal incorporation into foraminiferal calcite (Wolf-Gladrow \& Riebesell 1997; Wolf-Gladrow et al. 1999; Zeebe et al. 1999; Zeebe 1999). Elderfield et al. (1996) proposed a Rayleigh distillation model for trace element incorporation into foraminiferal $\mathrm{CaCO}_{3}$, which is consistent with data in benthic but not in planktonic foraminifera. As suggested by Zeebe \& Sanyal (2002), the process of metal incorporation is, particularly in the case of $\mathrm{Mg}^{2+}$, most likely intimately intertwined with the energetics of the precipitation mechanism itself (cf. also Erez 2003). Development of a comprehensive theory of element incorporation in foraminifera by means of mathematical and numerical modelling is currently an active area of palaeoceanographic research.

Parallel to the refinement of well-established proxy relationships such as $\delta^{13} \mathrm{C}$ and $\delta^{18} \mathrm{O}$ in foraminifera, other important geochemical proxies have been revitalized or newly developed over the past years, including metal/Ca ratios of $\mathrm{Mg}, \mathrm{Sr}, \mathrm{U}, \mathrm{Li}$ and stable calcium and boron isotopes. Stable boron isotope ratios in foraminifera provide a tool for reconstructing the $p \mathrm{H}$ of ancient seawater (e.g. Spivack et al. 1993; Hemming \& Hanson 1992; Sanyal et al. 1995; Pearson \& Palmer 2000; Hönisch \& Hemming 2005). The biogeochemical and physicochemical aspects of this 'palaeo-acidimetry' proxy have been intensively examined over the past years by culture studies with live planktonic species, inorganic precipitation experiments, and theoretical means including $a b$ initio molecular orbital theory (Sanyal et al. 1996, 2000, 2001; Hönisch et al. 2003; Hönisch \& Hemming 2004; Zeebe et al. 2001, 2003; Zeebe 2005a).

In this paper, we highlight some of our recent work on the development and validation of palaeoceanographic proxy relationships in foraminifera, primarily from a modeller's point of view. 'Vital effects and beyond' briefly describes the philosophy of our approach which is spelled out in terms of stable isotope fractionation in 'Stable isotope fractionation'. In 'Foraminifera dramatically alter their chemical and isotopic micro-environment' we show that foraminifera strongly perturb their chemical and isotopic microenvironment, which has immediate consequences for the palaeoceanographic interpretation of stable isotopes in foraminifera from the fossil record. Application of our method to stable boron isotopes and a downcore reconstruction of Late Pleistocene glacialinterglacial cycles in surface ocean $p \mathrm{H}$ is presented in 'Planktonic forminifera are reliable recorders of the ocean's palaeo- $p \mathrm{H}$ '. Finally, 'Foraminifera appear to control their shell-Mg/Ca ratio by a luxurious method' describes our findings that foraminifera seem to control their $\mathrm{Mg} / \mathrm{Ca}$ ratio by a rather expensive method in terms of energy requirements. The final section also points to several gaps in our understanding of biomineralization in foraminifera.

\section{Vital effects and beyond: the approach}

Our approach to proxy validation and development is based on complementary steps in exploring the inorganic chemistry, inorganic isotope fractionation and biological controls on proxy relationships in organisms relevant to climate reconstructions. In many cases, the integration of laboratory experiments, field and culture studies, theoretical considerations and numerical modelling has turned out to be a successful method for this task.

The foremost goal of this research is to improve climate reconstructions. Climate signals extracted from the geological record can be heavily overprinted by secondary, non-climate related phenomena because in the case of foraminifera, climate fluctuations are recorded by living organisms rather than by chemical compounds of inorganic origin. The long-term prospect of this work is to achieve refined palaeoceanographic interpretations of proxy relationships and to apply those relationships to the actual down-core record. The practical field application of our work to deep-sea sediment records has been documented by several authors of the present paper (e.g. Sanyal \& Bijma 1999; Zeebe 2001; Spero \& Lea 2002; Hönisch \& Hemming 2005).

\section{Stable isotope fractionation}

A great deal of our recent efforts has been focused on developing a comprehensive theory of stable isotope fractionation in foraminifera, focusing on the elements of carbon, oxygen and boron. While the inorganic $\mathrm{CO}_{2}$ chemistry and isotope 

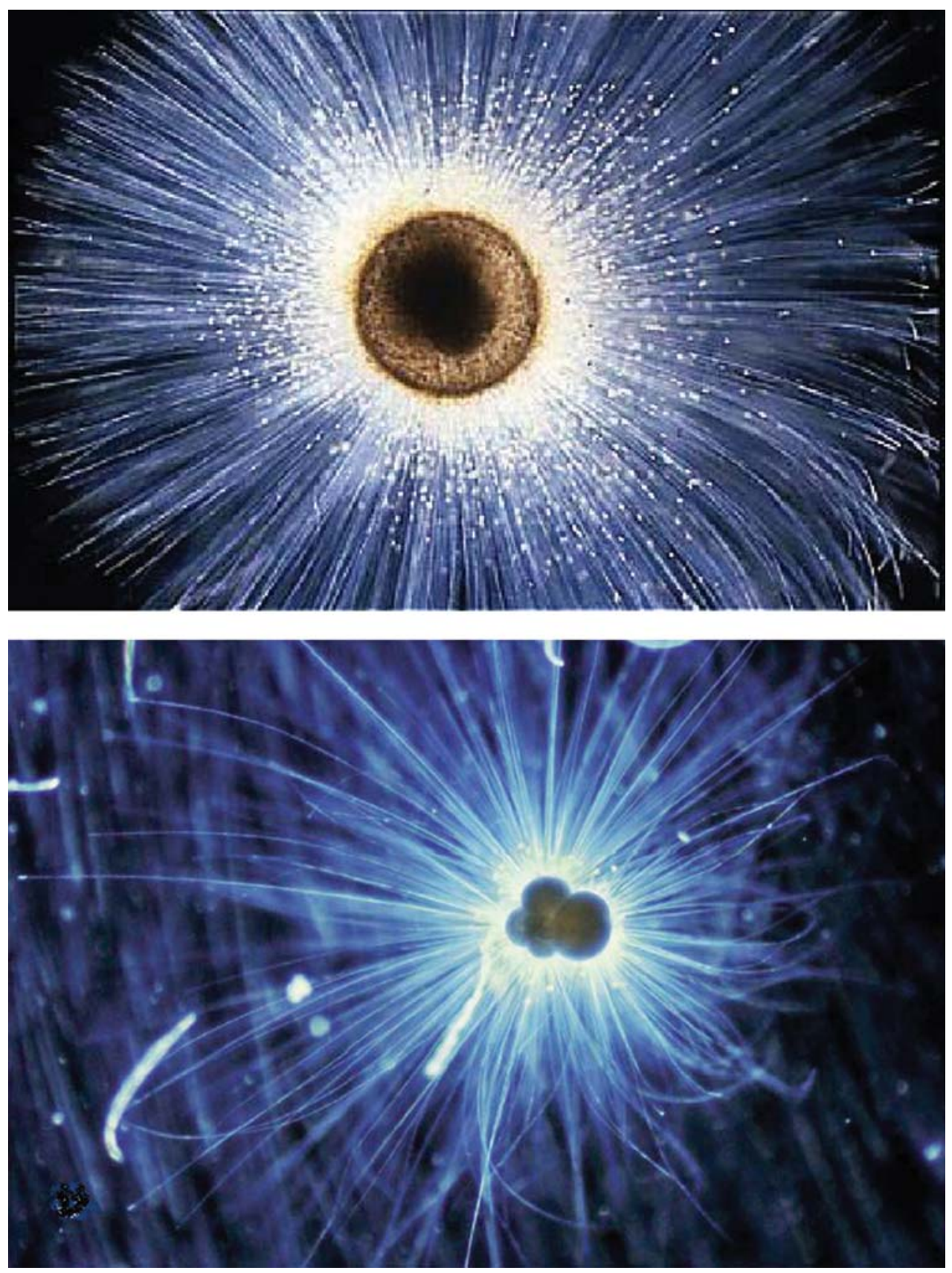

Fig. 1. Light microphotographs of the symbiotic, planktonic foraminifer Orbulina universa (top) and the non-symbiotic species Globigerina bulloides (bottom). After Spero (1998).

fractionation of carbon in the $\mathrm{CO}_{2}-\mathrm{H}_{2} \mathrm{O}-\mathrm{CaCO}_{3}$ system has been rather well known for quite some time now (for summary, see Millero 1995; Zhang et al. 1995; Zeebe \& Wolf-Gladrow 2001), this is not the case for oxygen (Usdowski \& Hoefs 1993;
Zeebe 1999; Zeebe 2005b) and less so for boron. In the following, the inorganic chemistry and stable isotope fractionation of dissolved boron in aqueous solution is used as an example to illustrate the steps taken in the process of understanding the 


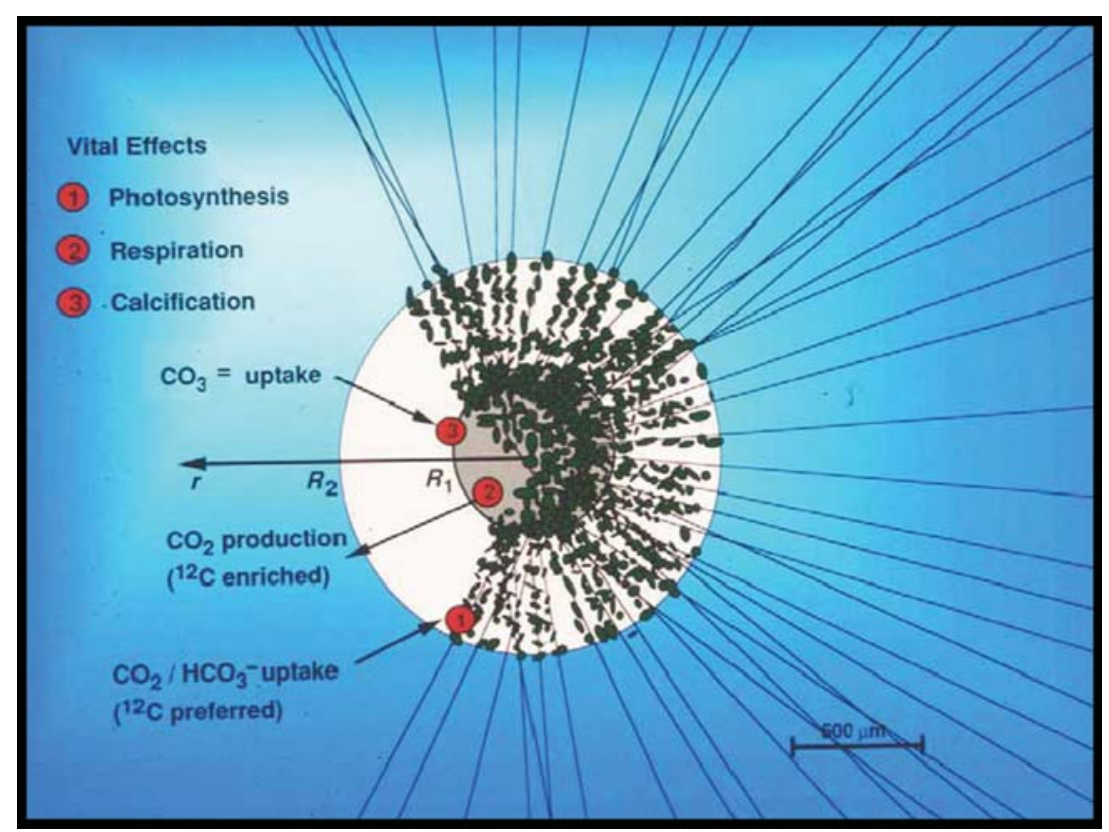

Fig. 2. Schematic of life processes. Photosynthesis, respiration, and calcification perturb the chemical and isotopic microenvironment of the organism. The distance to the centre of the shell is denoted by $r$, while $R_{1}$ and $R_{2}$ refer to the radius of the foraminiferal shell and edge of symbiont halo, respectively. Dissolved inorganic carbon depleted in ${ }^{13} \mathrm{C}$ is taken up during photosynthesis, while ${ }^{13} \mathrm{C}$-depleted $\mathrm{CO}_{2}$ is released during respiration (after Wolf-Gladrow et al. 1999; Zeebe et al. 1999).

thermodynamic basis of a proxy such as the $\delta^{11} \mathrm{~B}$ palaeo- $p \mathrm{H}$ proxy.

\section{Inorganic chemistry}

Dissolved boron in seawater comes mainly in two forms - as boric acid, $\mathrm{B}(\mathrm{OH})_{3}$, and borate ion, $\mathrm{B}(\mathrm{OH})_{4}^{-}$. The boric acid - borate equilibrium can be written as:

$$
\mathrm{B}(\mathrm{OH})_{3}+\mathrm{H}_{2} \mathrm{O} \leftrightarrows \mathrm{B}(\mathrm{OH})_{4}^{-}+\mathrm{H}^{+}
$$

with stoichiometric equilibrium constant $K_{\mathrm{B}}$ :

$$
K_{B}=\left[\mathrm{B}(\mathrm{OH})_{4}^{-}\right]\left[\mathrm{H}^{+}\right] /\left[\mathrm{B}(\mathrm{OH})_{3}\right]
$$

while the total boron concentration $B_{T}$ is given by

$$
B_{T}=\left[\mathrm{B}(\mathrm{OH})_{4}^{-}\right]+\left[\mathrm{B}(\mathrm{OH})_{3}\right]
$$

The concentration of the dissolved boron species as a function of $p \mathrm{H}$ is shown in Figure 3a. There is little discussion regarding the chemical thermodynamics of the boron equilibrium (cf. Zeebe \& Wolf-Gladrow 2001). A value frequently used for the dissociation constant of boric acid, $\mathrm{p} K_{\mathrm{B}}$, is 8.60 at $T=25^{\circ} \mathrm{C}, S=35$ (DOE 1994). It is also noted that at typical total boron concentration of $c .420$ $\mu \mathrm{mol} \mathrm{kg}{ }^{-1}$ in seawater, polynuclear boron species can probably safely be ignored. Cotton \& Wilkinson (1988) state that polynuclear boron species are negligible at concentrations $<25 \mathrm{mM}$ [see also $\mathrm{Su}$ \& Suarez (1995) and references therein]. Using $\mathrm{p} K$ 's for the polynuclear $\mathrm{B}_{3}$ species given in Kakihana et al. (1977), the concentration of $\mathrm{B}_{3} \mathrm{O}_{3}(\mathrm{OH})_{4}^{-}$, e.g. is $3 \times 10^{-11} \mathrm{M}$ at typical total seawater boron concentration.

On the other hand, the kinetics of the boric acid-borate equilibrium are less well known. Yet in order to calculate fluxes, $p \mathrm{H}$ gradient and boron isotope distribution in the vicinity of a foraminifer, the kinetics (i.e. the speed of the conversion between the two dissolved boron species) is crucial. At the time when we developed the numerical models of the chemical microenvironment of foraminifera there was, to the best of our knowledge, no measured value for this rate constant available in the literature. The problem was eventually solved by considering sound absorption data in seawater, which is described in Zeebe et al. (2001).

\section{Inorganic isotope fractionation}

Boron has two stable isotopes, ${ }^{10} \mathrm{~B}$ and ${ }^{11} \mathrm{~B}$, which make up $19.82 \%$ and $80.18 \%$ of the total boron (IUPAC 1998). As can be seen in Figure 3a, at 

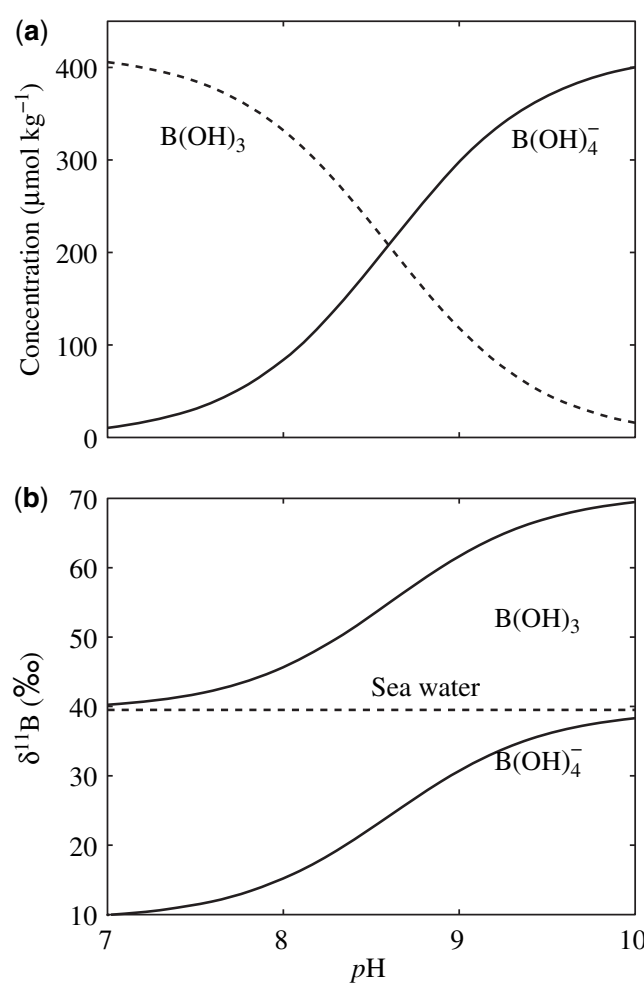

Fig. 3. (a) The concentration of dissolved boron species as a function of $p \mathrm{H}$ at $T=25^{\circ} \mathrm{C}, S=35$, and total boron concentration of $416 \mu \mathrm{mol} \mathrm{kg}^{-1}$ (DOE 1994). (b) Boron isotopic composition of $\mathrm{B}(\mathrm{OH})_{3}$ and $\mathrm{B}(\mathrm{OH})_{4}^{-}$as a function of $p \mathrm{H}$ assuming $\alpha_{\left(\mathrm{B}(\mathrm{OH})_{3}^{-}-\mathrm{B}(\mathrm{OH})_{4}^{-}\right)}=1.030$ (cf. Hemming \& Hanson 1992; Zeebe 2005a).

low $p \mathrm{H}$ all dissolved boron is essentially boric acid, $\mathrm{B}(\mathrm{OH})_{3}$, whereas at high $p \mathrm{H}$ all dissolved boron is essentially borate ion, $\mathrm{B}(\mathrm{OH})_{4}^{-}$. Because the stable isotope ${ }^{11} \mathrm{~B}$ is enriched in $\mathrm{B}(\mathrm{OH})_{3}$ compared to $\mathrm{B}(\mathrm{OH})_{4}^{-}$, the isotopic composition of the dissolved species change with $p \mathrm{H}$ (Fig. 3b). At low $p \mathrm{H}$ the isotopic composition of $\mathrm{B}(\mathrm{OH})_{3}$ is equal to the isotopic composition of the total dissolved boron, $\sim 39.5 \%$ o. On the other hand, at high $p \mathrm{H}$ the isotopic composition of $\mathrm{B}(\mathrm{OH})_{4}^{-}$is equal to the isotopic composition of the total dissolved boron. In between, the $\delta^{11} \mathrm{~B}$ of the two species increase. Based on the assumption that the charged species, $\mathrm{B}(\mathrm{OH})_{4}^{-}$, is incorporated into foraminiferal calcite (Hemming \& Hanson 1992), the $\delta^{11} \mathrm{~B}$ of calcite also increases with $p \mathrm{H}$ and a palaeo- $p \mathrm{H}$ proxy is created (Fig. 3b).

One uncertainty regarding the inorganic basis of this proxy is the value of the thermodynamic equilibrium fractionation factor between $\mathrm{B}(\mathrm{OH})_{3}$ and $\mathrm{B}(\mathrm{OH})_{4}^{-}, \alpha\left(\mathrm{B}(\mathrm{OH})_{3}^{-}-\mathrm{B}(\mathrm{OH})_{4}^{-}\right)$or, in short, $\alpha_{(\mathrm{B} 3-\mathrm{B} 4)}$. Based on the theory of thermodynamic properties of isotopic substances (Urey 1947), Kakihana \& Kotaka (1977) calculated $\alpha_{(\mathrm{B} 3-\mathrm{B} 4)}=1.0193$ at $300 \mathrm{~K}$. Due to the absence of an experimental value, this theoretical value has been widely used in geochemical applications over the past 25 years or so. However, recent theoretical work suggests a larger fractionation factor. In 2005, two theoretical articles were published indicating $\alpha_{(\mathrm{B} 3-\mathrm{B} 4)}>$ $\sim 1.030$ and $\alpha_{(\mathrm{B} 3-\mathrm{B} 4)}=1.027$ at $300 \mathrm{~K}$, respectively (Zeebe 2005a; Liu \& Tossell 2005). These results were based on various theoretical, analytical methods and on numerical approaches using $a b$ initio molecular orbital theory and point towards a larger value for $\alpha_{(\mathrm{B} 3-\mathrm{B} 4)}$, as also indicated by $\mathrm{Oi}$ (2000). Thus, theory predicts a value for the boron isotope fractionation factor between $\mathrm{B}(\mathrm{OH})_{3}$ and $\mathrm{B}(\mathrm{OH})_{4}^{-}$at $25^{\circ} \mathrm{C}$ of about $30 \%$ rather than $20 \%$. In fact, in the following year an experimental value of $28.5 \%$ was published (Byrne et al. 2006). It is emphasized that this is the fractionation factor between the dissolved boron compounds in solution and is not to be confused with fractionation factors involving stable boron isotope ratios in carbonates. The latter is discussed in the next section. In that context, it is important to note that when a fractionation of $28.5 \%$ is used to calculate the isotopic composition of borate, the shape and inflection point of the borate curve does not match the shape of the empirical carbonate data (Fig. 4).

The above example illustrates an aspect of a proxy relationship which requires more fundamental work because it is of basic, thermodynamic nature. Such hurdles need to be overcome by experimental and theoretical efforts. However, it would be erroneous to draw the general conclusion that a proxy approach whose inorganic basis is not yet completely understood is per se invalid. In the case of boron, e.g. uncertainties in $\alpha_{(\mathrm{B} 3-\mathrm{B} 4)}$ do not bias $p \mathrm{H}$ reconstructions provided that empirical organism-specific calibrations are used.

\section{Biological controls}

Some organism-specific calibrations are shown in Figure 4. They include results from controlled culture experiments with the two planktonic foraminiferal species Globigerinoides sacculifer and Orbulina universa (Sanyal et al. 1996, 2001) and the coral species Porites cylindrica and two species of Acropora (Hönisch et al. 2004; Reynaud et al. 2004).

First, the $\delta^{11} \mathrm{~B}$ of boron incorporated into the biogenic carbonates of all these coral and foraminiferal species increase with $p \mathrm{H}$. This is the basis of the $\delta^{11} \mathrm{~B}-p \mathrm{H}$ proxy. Second, there are offsets between different groups and species. The corals appear to be isotopically heavier 


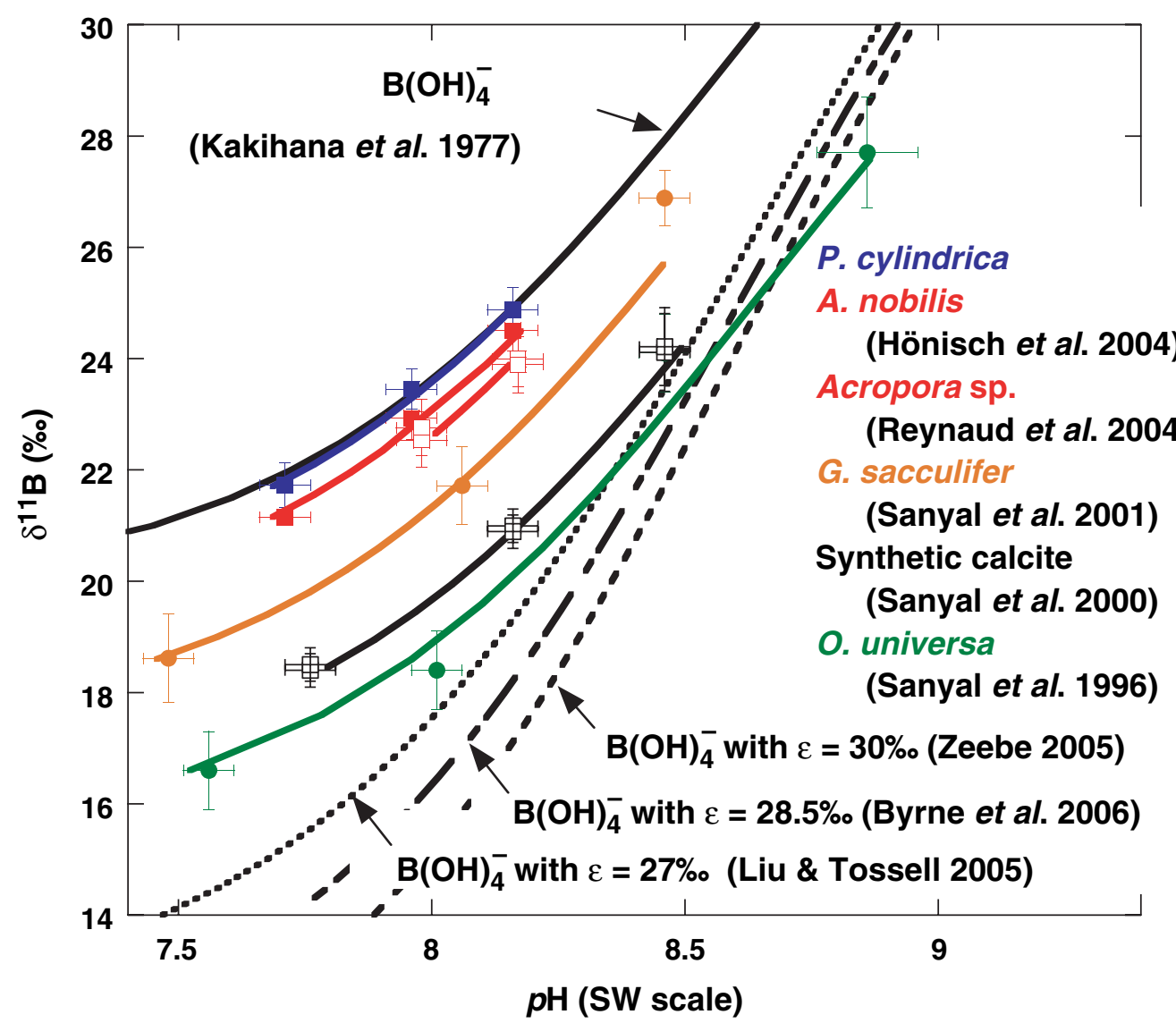

Fig. 4. Empirical relationships between $\delta^{11} \mathrm{~B}$ and culture seawater $p \mathrm{H}$ measured in three species of corals (Porites and Acropora), two species of planktonic foraminifera (Globigerinoides sacculifer and Orbulina universa), and inorganically precipitated calcite. Palaeoceanographic reconstructions use the empirical curves for reconstructing past seawater $p \mathrm{H}$. The upper black solid, the dotted, and the dashed black line represent the $\delta^{11} \mathrm{~B}$ of $\mathrm{B}(\mathrm{OH})_{4}^{-}$using $\alpha_{\text {(B3-B4) }}=1.019,1.027$, and 1.030 (Kakihana \& Kotaka 1977; Liu \& Tossell 2005; Zeebe 2005a). The dot-dashed black line represents the experimental $\alpha_{(\mathrm{B} 3-\mathrm{B} 4)}=1.0285$ of Byrne et al. (2006). Note that $\delta^{11} \mathrm{~B}_{\mathrm{B}(\mathrm{OH})_{4}^{-}}$and the $\delta^{11} \mathrm{~B}$ in carbonates are two different quantities and that one cannot be deduced from the other (see text).

(enriched in ${ }^{11} \mathrm{~B}$ ) compared to the foraminifera. It is interesting to note that the coral skeletons consist of the $\mathrm{CaCO}_{3}$ polymorph aragonite, while the foraminifera $G$. sacculifer and $O$. universa produce calcite shells. The offset between the two foraminiferal species is about $2 \%$ o. It is discussed in the next section that changes in the microenvironment of foraminifera can lead to light/dark shifts in shell $\delta^{11} \mathrm{~B}$. However, the offset between $G$. sacculifer and $O$. universa is difficult to explain with this mechanism (Zeebe et al. 2003). Also shown in Figure 4 are results for inorganically precipitated calcite (Sanyal et al. 2000) which falls between the foraminifera. In summary, the $\delta^{11} \mathrm{~B}-p \mathrm{H}$ relationship has been found in the biogenic carbonates tested. The foraminifera are offset from the inorganic calcite and the corals seem to be generally enriched relative to that.

So far only the isotopic fractionation between a standard and the carbonates as a function of $p \mathrm{H}$ has been discussed. Now let us look at the dissolved species of boron in aqueous solution. The upper black solid, the dotted, and the dashed black lines in Figure 4 represent the $\delta^{11} \mathrm{~B}$ of $\mathrm{B}(\mathrm{OH})_{4}^{-} \quad\left(\delta^{11} \mathrm{~B}_{\mathrm{B}(\mathrm{OH})_{4}^{-}}\right)$as a function of $p \mathrm{H}$ calculated using $\alpha_{(\mathrm{B} 3-\mathrm{B} 4)}=1.019,1.027$, and 1.030 (Kakihana \& Kotaka 1977; Liu \& Tossell 2005; Zeebe 2005a). The dot-dashed black line represents the experimental $\alpha_{(\mathrm{B} 3-\mathrm{B} 4)}=1.0285$ of Byrne et al. (2006). It is obvious that no matter what the true value of $\alpha_{(B 3-B 4)}$ is, the assumption that $\mathrm{B}(\mathrm{OH})_{4}^{-}$is exclusively 
incorporated into the carbonates without further fractionation cannot hold for all biogenic and inorganic carbonates. If this assumption was correct, then all carbonates would fall on a single line and this line would be the $\delta^{11} \mathrm{~B}$ of $\mathrm{B}(\mathrm{OH})_{4}^{-}$. As a corollary, $\delta^{11} \mathrm{~B}_{\mathrm{B}(\mathrm{OH})_{4}^{-}}$cannot be deduced from the $\delta^{11} \mathrm{~B}$ of the carbonates and vice versa. In the future, some remaining issues of the $\delta^{11} \mathrm{~B}-p \mathrm{H}$ proxy need to be addressed: (1) how does temperature, seawater salinity/composition, and total boron concentration affect the results for $\alpha_{(\mathrm{B} 3-\mathrm{B} 4)}$ published by Byrne et al. (2006); and (2) what causes the offsets between the $\delta^{11} \mathrm{~B}$ of the boron species in solution and in the carbonates. Meanwhile, neither of these questions compromises the use of $\delta^{11} \mathrm{~B}$ in carbonates as a palaeo- $p \mathrm{H}$ indicator.

\section{Foraminifera dramatically alter their chemical and isotopic micro-environment}

If one considers an organism of the size of a foraminifer $(R<1 \mathrm{~mm})$, being surrounded by a comparatively large volume of seawater, it may be difficult to see that the organism would have any significant influence on its environment. One would rather assume that the environmental properties the organism sees, and thus records in its shell, are dictated by the bulk seawater properties. Strictly, this is not the case. Although not independent of ambient conditions, the chemistry and isotopic ratios in the vicinity of the shell are primarily set by the properties within the diffusive boundary layer of the organism. The reason is that the typical length scale of the organism, $R$, is smaller than the so-called Kolmogorov scale, $\eta$, roughly the "size of the smallest eddie':

$$
\eta=\left(v^{3} / \varepsilon\right)^{1 / 4}
$$

where $v$ is the kinematic viscosity and $\varepsilon$ is the energy dissipation rate. In most parts of the ocean, $\eta$ is typically $>10 \mathrm{~mm}$, and $>1 \mathrm{~mm}$ in the wind mixed layer (Lazier \& Mann 1989). This means that the transport within the boundary layer of a foraminifer, for instance, is dominated by slow molecular diffusion rather than rapid turbulent mixing. The diffusion time scale on the millimetre scale $\left(L=10^{-3} \mathrm{~m}\right)$ is given by $\tau=L^{2} / D \cong 1000 \mathrm{~s}$ where $D=10^{-9} \mathrm{~m}^{2} \mathrm{~s}^{-1}$ is a diffusion coefficient characteristic for small molecules in seawater (note that diffusion on the length scale of single symbiotic algae, say a few micrometres, is much quicker). The combination of long diffusion time scales with high concentrations of symbionts and large rates of respiration and calcification of the foraminifera can drastically alter the microenvironment of the organism. As a result, the signal it encounters can be significantly different from that of the bulk medium. But how different?

Regarding foraminifera, this question has only recently been addressed using microsensor studies and numerical modelling (Jørgensen et al. 1985; Rink et al. 1998; Wolf-Gladrow et al. 1999; Zeebe et al. 1999; Zeebe et al. 2003). Figure 5 shows an example of a model experiment simulating a foraminifer under dark conditions (for details, see Wolf-Gladrow et al. 1999). Due to respiration, the $\mathrm{CO}_{2}$ concentration at the shell increases, while the $p \mathrm{H}$ drops (panels a and $\mathrm{d}$ ). Model results agree well with microsensor $p \mathrm{H}$ transects (diamonds in panel d, B. B. Jørgensen, pers. comm.). It is interesting to note that microsensor observations of $p \mathrm{H}$ and our model simulations are generally in good agreement also with more recent $p \mathrm{H}$ electrode studies (Rink et al. 1998; WolfGladrow et al. 1999). However, recent microelectrode measurements of dissolved $\mathrm{CO}_{2}$ show smaller dark/light $\mathrm{CO}_{2}$ amplitudes at the shell surface than the model (Köhler-Rink \& Kühl 2005). One possible explanation is that reaction rate constants as implemented in the model (based on inorganic chemistry) and those in the vicinity of the organism are different. Another is that in comparison to $p \mathrm{H}$ electrodes, the full potential of microsensor $\mathrm{CO}_{2}$ technology is yet to be reached.

Nevertheless, the important message is that at typical radii and life process fluxes of planktonic foraminifera, a boundary layer with strong chemical gradients is developed (this is not necessarily the case for other plankton, cf. Wolf-Gladrow \& Riebesell 1997). This leads to substantial differences between e.g. $p \mathrm{H}$ and $\mathrm{O}_{2} / \mathrm{CO}_{2}$ concentrations in the vicinity of the organism and the ambient seawater. For example, in symbiotic foraminifera under high-light conditions, $\mathrm{O}_{2}$ has been measured to be 2 to 2.5 times higher at the shell than in the bulk medium, while measured and simulated $p \mathrm{H}$ rises by more than 0.4 units at the shell (Jørgensen et al. 1985; Rink et al. 1998; Wolf-Gladrow et al. 1999; Köhler-Rink \& Kühl 2005). During night time, and when ambient $p \mathrm{H}$ is lowered below typical seawater values $(p \mathrm{H}<\sim 7.7$, HJS and JB, unpublished results), acidic conditions at the shell due to $\mathrm{CO}_{2}$ respiration can lead to calcification inhibition or actual dissolution of calcite chambers.

But not only is the chemistry within the foraminiferal boundary layer drastically perturbed. Stable isotope ratios are also affected, which bears directly on palaeoceanographic interpretations of stable isotopes in fossil foraminifera. For example, preferential uptake of ${ }^{12} \mathrm{C}$ during symbiont photosynthesis under light conditions leads to enrichment of 
(a)

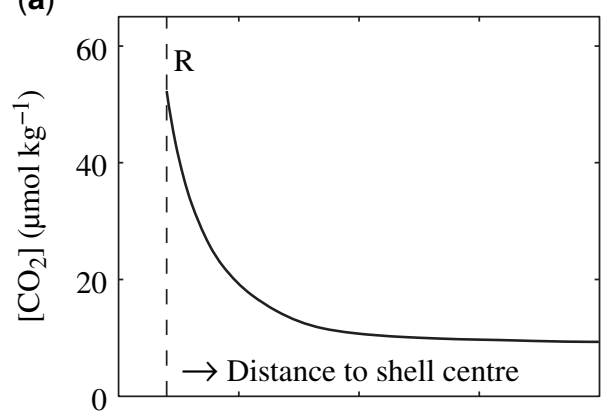

(c)

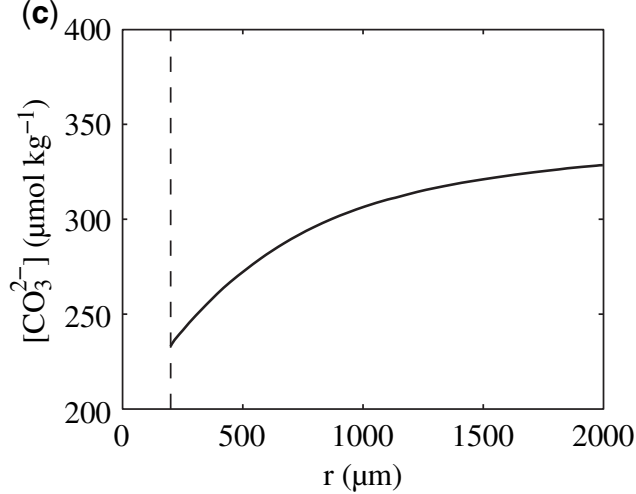

(b)

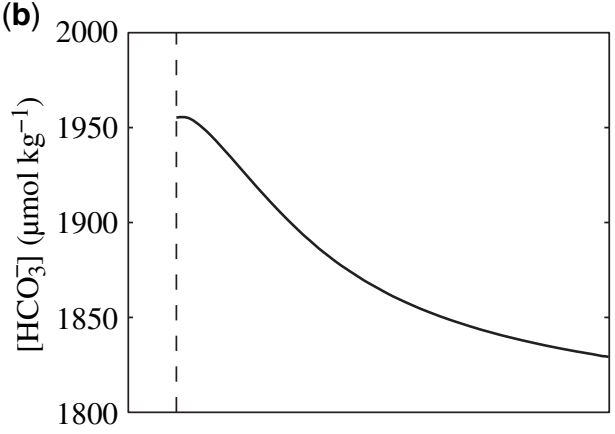

(d)

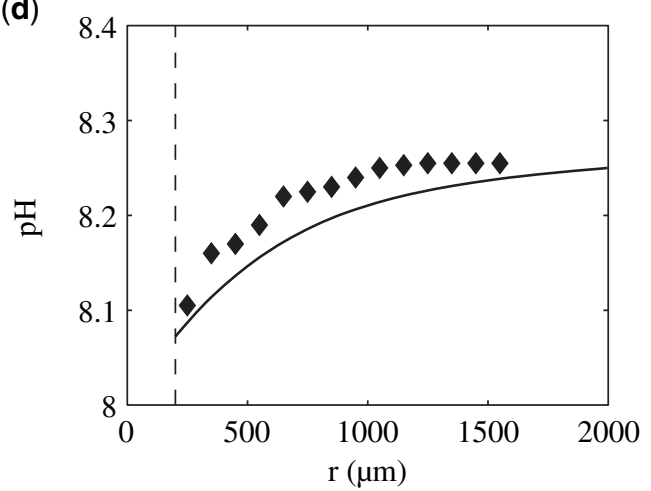

Fig. 5. Results of a diffusion-reaction model of the foraminiferal microenvironment under dark conditions. (a) Respiration raises $\mathrm{CO}_{2}$ at the shell, while $\left[\mathrm{CO}_{2}^{3-}\right]$ and $p \mathrm{H}$ decrease $(\mathbf{c}, \mathbf{d})$. (b) The $\mathrm{HCO}_{3}^{-}$pool is large and shows relatively small changes $(<7 \%)$ under dark conditions (this is different under high-light, Wolf-Gladrow et al. 1999). Microsensor $p \mathrm{H}$ transects (diamonds in panel d) were measured by B. B. Jørgensen and co-workers.

shell- $\delta{ }^{13} \mathrm{C}$ by up to $1.5 \%$ (Spero \& Williams 1988), in agreement with results of diffusion-reaction models which include stable carbon isotopes (Zeebe et al. 1999). Likewise, it is not difficult to imagine that stable boron isotope ratios at the shell are different under light vs. dark conditions, considering the substantial $p \mathrm{H}$ variations at the shell (Fig. 5d). In fact, controlled laboratory experiments and numerical modelling has shown this to be the case (Hönisch et al. 2003; Zeebe et al. 2003).

Figure 6 illustrates the differences in shell $\delta^{11} \mathrm{~B}$ in the dark and light, respectively. In the dark, $p \mathrm{H}$ at the shell is lowered, and, considering that $\delta^{11} \mathrm{~B}_{\mathrm{B}(\mathrm{OH})_{4}^{-}}$decreases with $p \mathrm{H}$ (Fig. 3b), shell $\delta^{11} \mathrm{~B}$ is lowered as well - provided that $\mathrm{B}(\mathrm{OH})_{4}^{-}$is preferentially incorporated into the calcite. The opposite applies to high-light conditions. Although the sign of the light/dark induced $\delta^{11} \mathrm{~B}$ shift is clear, its magnitude could not be calculated until the kinetics of the boric acid-borate ion reaction were understood. (Note that the boundary layer chemistry

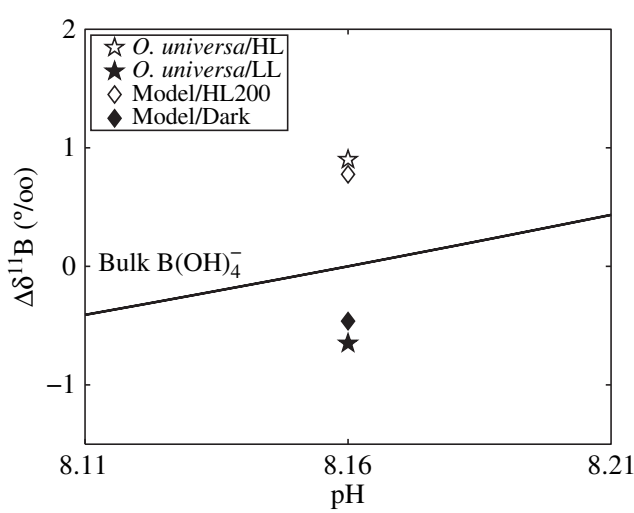

Fig. 6. Light/dark induced shift in shell $\delta^{11} \mathrm{~B}$ of $O$. universa as measured in culture experiments (stars) and numerically simulated (diamonds). $\Delta \delta^{11} \mathrm{~B}$ is the difference relative to bulk $\delta^{11} \mathrm{~B}_{\mathrm{B}(\mathrm{OH})_{4}^{-}}$at $p \mathrm{H} 8.16 ; \mathrm{HL}=$ High Light; $\mathrm{LL}=$ Low Light. Experimental and modeled total dissolved boron concentration were 10 times elevated over natural seawater concentrations. In the model, a symbiont halo thickness of $200 \mu \mathrm{m}$ was assumed (HL200). 


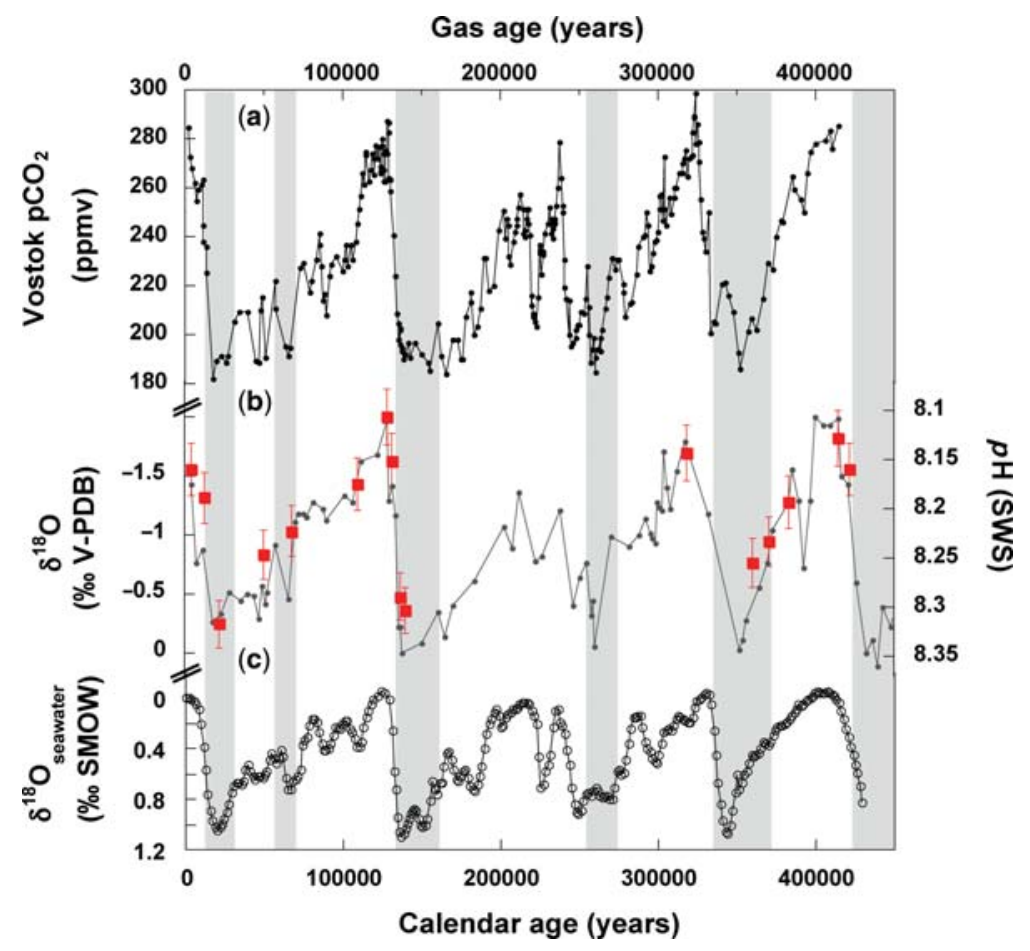

Fig. 7. Reconstruction of surface ocean $p \mathrm{H}$ over glacial cycles based on $\delta^{11} \mathrm{~B}$ (Hönisch \& Hemming 2005). (a) Past atmospheric $\mathrm{CO}_{2}$ concentration from the Vostok ice core (Petit et al. 1999). (b) $\delta^{11} \mathrm{~B}$ in Globigerinoides sacculifer from ODP core 668B in the eastern equatorial Atlantic, Sierra Leone Rise at $2693 \mathrm{~m}$ water depth (right axis, red symbols) superimposed on $\delta^{18} \mathrm{O}$ of Globigerinoides ruber (left axis, black symbols). (c) Record of $\delta^{18} \mathrm{O}$ of seawater, reflecting changes in global ice volume (Waelbroeck et al. 2002). Note that surface $p \mathrm{H}$ reconstructions track the glacial-interglacial climate oscillations in agreement with inferred changes from ice-core $\mathrm{CO}_{2}$.

is properly described by a steady-state of fluxes involving diffusion and reaction kinetics. It is not chemical equilibrium.) Taking advantage of our previous work on the boric acid-borate ion kinetics described in the 'Inorganic Chemistry' section (Zeebe et al. 2001), the light/dark induced $\delta^{11} \mathrm{~B}$ shift was calculated (Fig. 6). The model results using 10 times elevated total boron concentration (as in culture experiments) and a symbiont halo thickness of $200 \mu \mathrm{m}$ match experimental results well (Hönisch et al. 2003; Zeebe et al. 2003).

\section{Planktonic foraminifera are reliable recorders of the ocean's palaeo- $p H$}

Reliable proxies for the ocean's $\mathrm{CO}_{2}$ chemistry are of utmost importance because they can provide information about past atmospheric $\mathrm{CO}_{2}$ concentrations and clues to the causes of carbon cycle variations. In turn, such information is crucial to comprehending feedbacks of Earth's climate system. For example, due to lack of adequate $\mathrm{CO}_{2}$ records, it is still controversial whether $\mathrm{CO}_{2}$ was the primary driver of the Cenozoic cooling trend. Moreover, we still lack a sound understanding of the link between glacial-interglacial changes in atmospheric $\mathrm{CO}_{2}$ and deep ocean chemistry. These problems need to be solved by reliable $\mathrm{CO}_{2-}$ system reconstructions. As described earlier, stable boron isotope ratios in foraminifera provide a tool for reconstructing the $p \mathrm{H}$ of ancient seawater (Spivack et al. 1993; Sanyal et al. 1995; Pearson \& Palmer 2000; Hönisch \& Hemming 2005); combined with information on one other parameter of the carbonate system (e.g. $\mathrm{CO}_{3}^{2-}$, total $\mathrm{CO}_{2}$, or total alkalinity), past atmospheric $\mathrm{pCO}_{2}$ may be estimated (e.g. Tyrrell \& Zeebe 2004).

Efforts to understand and calibrate this proxy, including culture experiments, inorganic precipitation studies, and theoretical approaches hitherto indicate that planktonic foraminifera are reliable recorders of the ocean's palaeo- $p \mathrm{H}$ (Sanyal et al. 1995, 1996, 2000, 2001; Hönisch et al. 2003; 


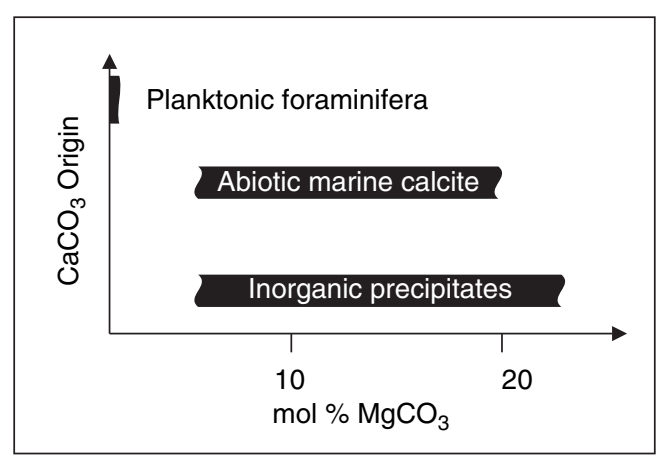

Fig. 8. Typical values of mole $\% \mathrm{MgCO}_{3}$ in planktonic foraminifera, abiotic marine calcite, and inorganic precipitates from laboratory studies.

Hönisch \& Hemming 2004; Zeebe et al. 2001, 2003; Zeebe 2005a). Assuming the modern relationship between alkalinity and salinity remained constant over the course of the Pleistocene, Sanyal et al. (1995) and Hönisch \& Hemming (2005) translated their $\delta^{11} \mathrm{~B}-p \mathrm{H}$ reconstructions (Fig. 7) and estimated alkalinities into aqueous $\mathrm{pCO}_{2}$ estimates, which quantitatively reflect atmospheric $\mathrm{pCO}_{2}$ reconstructions measured in ice cores (Petit et al. 1999; Siegenthaler et al. 2005).

Whereas surface ocean $p \mathrm{H}$ estimates have never been questioned, boron isotope estimates of a dramatic glacial deep-sea increase in $p \mathrm{H}$ and $\left[\mathrm{CO}_{3}^{2-}\right]$ (Sanyal et al. 1995) could not be confirmed by sedimentary records of carbonate preservation and other geochemical proxy records. Deep sea $p \mathrm{H}$ estimates have therefore been criticized (Broecker \& Henderson 1998). The major uncertainty of those estimates was the use of mixed benthic foraminifer species, which are likely to record a mix of $p \mathrm{H}$ conditions from pore and bottom waters. A recent sediment study now focusing on the use of the single epibenthic foraminifer species Cibicidoides wuellerstorfi, found glacial deep water $p \mathrm{H}$ in the Atlantic similar to or no higher than $+0.08 p \mathrm{H}$ units relative to interglacials (Hönisch et al. in press). These new data no longer support the hypothesis of a much more basic deep ocean which could explain the entire glacial drop in atmospheric $\mathrm{pCO}_{2}$. More validation studies for the Pacific Ocean are underway but the studies mentioned above demonstrate that the boron isotope proxy is a useful tool, if carefully applied.

\section{Foraminifera appear to control their shell-Mg/Ca ratio by a luxurious method}

$\mathrm{Mg} / \mathrm{Ca}$ ratios in carbonates and seawater affect the thermodynamic equilibrium between solution and the solid state, as well as the kinetics during crystal precipitation and dissolution. These properties are relevant for global carbon, calcium, and magnesium fluxes (Morse \& Mackenzie 1990) and were likely important drivers of switches between Phanerozoic calcite and aragonite seas (Stanley \& Hardie 1998). More recently, $\mathrm{Mg} / \mathrm{Ca}$ ratios in foraminifera have received great attention because of their use as a palaeothermometer (e.g. Nürnberg et al. 1996; Lea et al. 2000; Tripati \& Elderfield 2005).

Planktonic foraminifera seem to have strong control over their shell $\mathrm{Mg}$ concentration because the $\mathrm{Mg} / \mathrm{Ca}$ ratio is significantly smaller than, for instance, of abiotic marine calcite or inorganically precipitated calcite in the laboratory (Fig. 8). The latter two fall in the category of high-magnesian calcites. Because $\mathrm{Mg}^{2+}$ is also known to be an inhibitor of calcite growth, one viable strategy of planktonic foraminifera to initiate calcite precipitation may be the removal of $\mathrm{Mg}^{2+}$ ions from the site of calcification. If there are other advantages to produce low- instead of high-magnesian calcite (related to thermodynamic stability, for instance), then $\mathrm{Mg}^{2+}$ removal would serve two purposes at the same time. Zeebe \& Sanyal (2002) investigated such a scenario by means of inorganic precipitation experiments. The purpose of the experiments was to mimic the chemistry of a calcifying fluid during precipitation, analogous to a simple calcification scheme as depicted in Figure 9 (for a recent

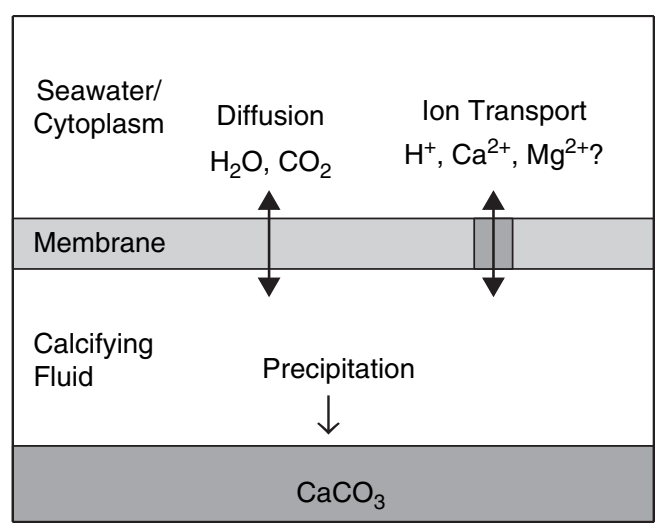

Fig. 9. Simple calcification scheme of $\mathrm{CaCO}_{3}$ precipitation from a calcifying fluid. Organisms may control precipitation by separating a certain space from the ambient seawater by a membrane which is permeable to $\mathrm{H}_{2} \mathrm{O}$ and $\mathrm{CO}_{2}$ diffusion. Ion transport across the membrane may be mediated by $\mathrm{H}^{+}$-ATPase and $\mathrm{Ca}^{2+}$-ATPase. Note that whether such transport systems are active in foraminifera remains to be tested; even less is known about magnesium transporters. 
review of biomineralization in foraminifera, see Erez 2003).

The evaluation of the experimental results plus consideration of $\mathrm{H}^{+}, \mathrm{CO}_{2}$, and $\mathrm{Ca}^{2+}$ fluxes indicate that it is energetically much more efficient to initiate calcite precipitation by removal of protons, rather than $\mathrm{Mg}^{2+}$ ions (Zeebe \& Sanyal 2002). This result is puzzling because the low $\mathrm{Mg}$ concentrations in planktonic foraminifera are then difficult to explain by considering costeffectiveness during 'house building'. Of course, it is well known that the cheaper house is not necessarily the better one and other factors may be important for the low $\mathrm{Mg} / \mathrm{Ca}$ ratios in planktonic foraminifera. Alternatively, calcification mechanisms could also involve $\mathrm{Mg}^{2+}$-binding organic ligands. Such avenues should be explored in the future in order to solve the puzzle of biomineralization in foraminifera.

Recent advances in measurement techniques allow analysis of ever smaller samples. Eggins et al. (2004) used high-resolution microanalysis techniques to study the spatial distribution of $\mathrm{Mg}$ in the final chamber of the planktonic foraminifer Orbulina universa. They found paired bands of low and high $\mathrm{Mg} / \mathrm{Ca}$ ratios which were interpreted as diurnal growth bands reflecting $p \mathrm{H}$ changes in the foraminiferal microenvironment driven mainly by variations in photosynthesis and respiration of the symbionts. They speculate that the $\mathrm{Mg}$ banding may be accompanied by similar variations in oxygen, carbon and boron isotopes. If this is true and measurable (cf. Rollion-Bard 2005) it would open the door to investigating stable isotope variations at the sub-shell/sub-chamber scale of foraminifera. Element and isotope variations across a single foraminiferal shell pose a new challenge for models of biomineralization.

\section{Conclusions}

In this paper we have primarily reviewed some of our recent work on developing and validating palaeoceanographic proxy relationships in foraminifera. Several aspects of the biology and geochemistry of planktonic foraminifera relevant to climate reconstructions have been explored in great detail over the last 10 years or so. A few conclusions derived from this research were discussed in the current paper: (1) foraminifera dramatically alter their chemical and isotopic micro-environment; (2) planktonic foraminifera are reliable recorders of the ocean's $p \mathrm{H}$; and (3) foraminifera appear to control their shell-Mg/Ca ratio by a luxurious method. Our results were obtained by a team effort, combining culture studies of live foraminifera, laboratory studies and theoretical work. In order to employ the full potential of palaeoceanographic proxies that involve once living organisms, the approach outlined in the current paper has turned out to be successful in many cases. We conclude that future research should continue to employ this approach.

David Lea, Ann Russell and the many students and research colleagues are acknowledged who participated in various field campaigns that produced the experimental data discussed in this paper. Experimental research described here was supported by the National Science Foundation and DFG (Palaeoprox: BI 432/3) and the European Commission (6C: EVK2-CT-2002-00135) to J. B. Support to R. E. Z. was provided by the National Science Foundation (NSF-OCE05-25647)

\section{References}

Bé, A. W. H., Hemleben, C., Anderson, O. R., SPINDler, M., Hacunda, J. \& Tuntivate-ChoY, S. 1977. Laboratory and field observations of living planktonic foraminifera. Micropaleontology, $\mathbf{2 3}$, $155-179$.

Bice, K. L., Birgel, D., Meyers, P. A., Dahl, K. A., HinRICHS, K.-U. \& NorRIS, R. D. 2006. A multiple proxy and model study of Cretaceous upper ocean temperatures and atmospheric $\mathrm{CO}_{2}$ concentrations. Paleoceanography, 21, PA2002, doi:10.1029/ 2005PA001203.

Bijma, J., Hemleben, C., Huber, B. T., ERlenkeuser, H. \& KROON, D. 1998. Experimental determination of the ontogenetic stable isotope variability in two morphotypes of Globigerinella siphonifera (d'Orbigny). Marine Micropaleontology, 35, 141-160.

BiJMA, J., SPERO, H. J. \& LEA, D. W. 1999. Reassessing foraminiferal stable isotope geochemistry: impact of the oceanic carbonate system (experimental results). In: Fischer, G. \& WefER, G. (eds) Use of Proxies in Paleoceanography: Examples from the South Atlantic, Springer-Verlag, Berlin, 489-512.

Byrne, R. H., YaO, W., KlochKo, K., Tossell, J. A. \& KAUfMAN, A. J. 2006. Experimental evaluation of the isotopic exchange equilibrium ${ }^{10} \mathrm{~B}(\mathrm{OH})_{3}+$ ${ }^{11} \mathrm{~B}(\mathrm{OH})_{4}^{-}={ }^{11} \mathrm{~B}(\mathrm{OH})_{3}+{ }^{10} \mathrm{~B}(\mathrm{OH})_{4}^{-}$in aqueous solution. Deep-Sea Research I, 53, 684-688.

Bouvier-SoumagnaC, Y. \& Duplessy, J.-C. 1985 Carbon and oxygen isotopic composition of planktonic foraminifera from laboratory culture, plankton tows and recent sediment: implications for the reconstruction of paleoclimatic conditions and of the global carbon cycle. Journal of Foraminifera Research, 15, 302-320.

Broecker, W. S. \& Henderson, G. M. 1998. The sequence of events surrounding Termination II and their implications for the cause of glacial-interglacial changes. Paleoceanography, 13, 352-364.

Cotton, F. A. \& Wilkinson, G. 1988. Advanced Inorganic Chemistry: A Comprehensive Text (5th ed.). Wiley, New York.

DOE. 1994. Handbook of Methods for the Analysis of the Various Parameters of the Carbon Dioxide System in Sea Water; Version 2. In: DICKSON, A. G. \& GOYET, C. (eds) ORNL/CDIAC-74. 
Eggins, S. M., SAdekov, A. \& DE DeckKer, P. 2004. Modulation and daily banding of $\mathrm{Mg} / \mathrm{Ca}$ in Orbulina universa tests by symbiont photosynthesis and respiration: a complication for seawater thermometry? Earth and Planetary Science Letters, 225, 411-419.

Elderfield, H., Bertram, C. J. \& ERez, J. 1996. A biomineralization model for the incorporation of trace elements into foraminiferal calcium carbonate. Earth and Planetary Science Letters, 142, 409-423.

EMILIANI, C. 1955. Pleistocene temperatures. Journal of Geology, 63, 538-578.

EREZ, J. 2003. The source of ions for biomineralization in foraminifera and their implications for paleoceanographic proxies. Review in Mineralogy and Geochemisty, 54, 115-149.

Hemleben, C., Be, A. W. H., Anderson, O. R. \& Tuntivate-Choy, S. 1977. Test morphology, organic layers and chamber formation of the planktonic foraminifer Globorotalia menardii (d'Orbigny). Journal of Foraminifera Research, 1-25.

Hemleben, C., Spindler, M., Breitinger, I. \& Deuser, W. G. 1985. Field and laboratory studies on the ontogeny and ecology of some Globorotaliid species from the Sargasso Sea off Bermuda. Journal of Foraminifera Research, 15, 254-272.

Hemming, N. G. \& HANSON, G. N. 1992. Boron isotopic composition and concentration in modern marine carbonates. Geochimica et Cosmochimica Acta, 56, $537-543$.

Hönisch, B. \& Hemming, N. G. 2004. Ground-truthing the boron isotope paleo- $p \mathrm{H}$ proxy in planktonic foraminifera shells: partial dissolution and shell size effects. Paleoceanography, 19 PA4010, doi: 10.1029/2004PA001026.

HönISCH, B. \& Hemming, N. G. 2005. Surface ocean $p H$ response to variations in $\mathrm{pCO}_{2}$ through two full glacial cycles. Earth and Planetary Science Letters, 236, 305-314.

Hönisch, B., Bijma, J., Russell, A. D., Spero, H. J., Palmer, M. R., Zeebe, R. E. \& Eisenhauer, A. 2003. The influence of symbiont photosynthesis on the boron isotopic composition of foraminifera shells. Marine Micropaleontology, 49, doi:10.1016/ S0377-8398(03)00030-6.

Hönisch, B., Hemming, N. G., Grottoli, A. G., Amat, A., Hanson, G. N. \& Bijma, J. 2004. Assessing scleractinian corals as recorders for paleo- $p \mathrm{H}$ : empirical calibration and vital effects. Geochimica et Cosmochimica Acta, 68, 3675-3685.

Hönisch, B., Bickert, T. \& Hemming, N. G. 2008. Modern and pleistocene boron isotope composition of the benthic foraminifer Cibicidoides Wuellerstrorfi, Earth and Planetary Science Letters, in press.

IUPAC. 1998. Isotopic compositions of the elements 1997. Pure Applied Chemistry, 70, 217-235.

Jørgensen, B. B., Erez, J., Revsbech, N. P. \& CoHEN, Y. 1985. Symbiotic photosynthesis in a planktonic foraminiferan, Globigerinoides sacculifer (Brady), studied with microelectrodes. Limnology Oceanography, 30, 1253-1267.

Kakihana, H. \& KotaKa, M. 1977. Equilibrium constants for boron isotope-exchange reactions. Bulletin of Research Laboratory for Nuclear Reactions, 2, 1-12.
Kakihana, H., Kotaka, M., Satoh, S., Nomura, M. \& OKАмото, M. 1977. Fundamental studies on the ion-exchange separation of boron isotopes. Bulletin of the Chemical Society of Japan, 50, 158-163.

KÖHLER-RINK, S. \& KÜHL, M. 2005. The chemical microenvironment of the symbiotic planktonic foraminifer Orbulina universa. Marine Biology Research, 1, 68-78.

LAZIER, J. R. N. \& MANN, K. H. 1989. Turbulence and the diffusive layers around small organism. Deep-Sea Research, 36, 1721-1733.

LeA, D. W., PAK, D. K. \& Spero, H. J. 2000. Climate impact of late Quaternary equatorial Pacific sea surface temperature variations. Science, 289, 1719-1724.

LiU, Y. \& Tossell, J. A. 2005. Ab initio molecular orbital calculations for boron isotope fractionations on boric acids and borates. Geochimica et Cosmochimica Acta, 69, 3995-4006.

MilleRO, F. J. 1995. Thermodynamics of the carbon dioxide system in the oceans. Geochimica et Cosmochimica Acta, 59, 661-677.

Morse, J. W. \& MackenzIE, F. T. 1990. Geochemistry of Sedimentary Carbonates. Developments in Sedimentology, 48, Elsevier, Amsterdam.

Nürnberg, D., Bijma, J. \& Hemleben, C. 1996. Assessing the reliability of magnesium in foraminiferal calcite as a proxy for water mass temperatures. Geochimica et Cosmochimica Acta, 60, 803-814; Erratum 2483-2484.

OI, T. 2000. Calculations of reduced partition function ratios of monomeric and dimeric boric acids and borates by the $a b$ initio molecular orbital theory. Journal of Nuclear Science and Technology, 37, $166-172$.

Pearson, P. N. \& Palmer, M. R. 2000. Atmospheric carbon dioxide concentrations over the past 60 million years. Nature, 406, 695-699.

Petit, J. R., Jouzel, J., Raynaud, D. ET AL. 1999. Climate and atmospheric history of the past 420,000 years from the Vostok ice core, Antarctica. Nature, 399, 429-436.

Reynaud, S., Hemming, G. N., Juillet-Leclerc, A. \& GATTUSO, J.-P. 2004. Effect of $\mathrm{pCO}_{2}$ and temperature on the boron isotopic composition of the zooxanthellate coral Acropora sp. Coral Reefs, 23, 539-546.

Rink, S., KÜHL, M., BIJMA, J. \& Spero, H. J. 1998. Microsensor studies of photosynthesis and respiration in the symbiotic foraminifer Orbulina universa. Marine Biology, 131, 583-595.

ROLLION-BARD, C. 2005. Microanalysis by ion microprobe of oxygen isotopic compositions in foraminifera. Geophysical Research Abstracts, 7, 1607-7962.

Royer, D. L., Berner, R. A., Montanez, I. P., TABor, N. J. \& BEERLING, D. J. 2004. $\mathrm{CO}_{2}$ as a primary driver of Phanerozoic climate change. GSA Today, 14, 4-10.

Sanyal, A. \& BiJma, J. A. 1999. Comparative study of the northwest Africa and eastern equatorial Pacific upwelling zones as sources of $\mathrm{CO}_{2}$ during glacial periods based on boron isotope paleo- $p \mathrm{H}$ estimation. Paleoceanography, 14, 753-759.

Sanyal, A., Hemming, N. G., Hanson, G. N. \& BROECKER, W. S. 1995. Evidence for a higher $p \mathrm{H}$ in the glacial ocean from boron isotopes in foraminifera. Nature, 373, 234-236. 
SAnyal, A., Hemming, N. G., Broecker, W. S., LeA, D. W., Spero, H. J. \& Hanson, G. N. 1996. Oceanic $p \mathrm{H}$ control on the boron isotopic composition of foraminifera: evidence from culture experiments. Paleoceanography, 11, 513-517.

Sanyal, A., Nugent, M., Reeder, R. J. \& Bijma, J. 2000. Seawater $p \mathrm{H}$ control on the boron isotopic composition of calcite: evidence from inorganic calcite precipitation experiments. Geochimica et Cosmochimica Acta, 64, 1551-1555.

Sanyal, A., Bijma, J., Spero, H. J. \& Lea, D. W. 2001. Empirical relationship between $p \mathrm{H}$ and the boron isotopic composition of Globigerinoides sacculifer: Implications for the boron isotope paleo- $\mathrm{pH}$ proxy. Paleoceanography, 16, 515-519.

ShaCKLETON, N. J. 1967. Oxygen isotope analysis and Pleistocene temperatures re-assessed. Nature, 215, 15-17.

Siegenthaler, U., Stocker, T. F., Monnin, E., LÜthi, D., SchWander, J., Stauffer, B., Raynaud, D., BARnola, J.-M., Fischer, H., Masson-Delmotte, V. \& Jouzel, J. 2005. Stable carbon cycle-climate relationship during the Late Pleistocene. Science, 310, 1313-1317.

SPERO, H. J. 1998. Life history and stable isotope geochemistry of planktonic foraminifera. In: NORRIS, R. D. \& CORFIELD, R. M. (eds) Isotope Paleobiology and Paleoecology; Paleontological Society Papers, 4, 7-36.

Spero, H. J. \& DeNiro, M. J. 1987. The influence of symbiont photosynthesis on the $\delta^{18} \mathrm{O}$ and $\delta^{13} \mathrm{C}$ values of planktonic foraminiferal shell calcite. Symbiosis, 4, 213-228.

SPERO, H. J. \& LEA, D. W. 1993. Intraspecific stable isotope variability in the planktic foraminifera Globigerinoides sacculifer: Results from laboratory experiments. Marine Micropaleontology, 22, 221-234.

SPERO, H. J. \& LEA, D. W. 1996. Experimental determination of intraspecific stable isotope variability in Globigerina bulloides: Implications for paleoceanographic reconstructions. Marine Micropaleontology, 28, 231-246.

Spero, H. J. \& LEA, D. W. 2002. The cause of carbon isotope minimum events on glacial terminations. Science, 296, 522-525.

Spero, H. J. \& Williams, D. F. 1988. Extracting environmental information from planktonic foraminiferal $\delta^{13} \mathrm{C}$ data. Nature, 335, 717-719.

Spero, H. J., Lerche, I. \& Williams, D. F. 1991. Opening the carbon isotope "vital effect" black box, 2 , quantitative model for interpreting foraminiferal carbon isotope data. Paleoceanography, 6, 639-655.

Spero, H. J., Bijma, J., LeA, D. W. \& Bemis, B. E. 1997. Effect of seawater carbonate concentration on foraminiferal carbon and oxygen isotopes. Nature, 390, 497-500.

SpivaCK, A. J., You, C.-F. \& SMith, H. J. 1993. Foraminiferal boron isotope ratios as a proxy for surface ocean $p \mathrm{H}$ over the past $21 \mathrm{Myr}$. Nature, 363, 149-151.

Stanley, S. M. \& Hardie, L. A. 1998. Secular oscillations in the carbonate mineralogy of reef-building and sediment-producing organisms driven by tectonically forced shifts in seawater chemistry. Palaeogeography, Palaeoclimatology, Palaeoecology, 144, 3-19.
Su, C. \& SuAREz, D. L. 1995. Coordination of adsorbed boron: a FTIR spectroscopic study. Environmental Science and Technology, 29, 302-311.

Tripati, A. \& Elderfield, H. 2005. Deep-sea temperature and circulation changes at the Paleocene-Eocene thermal maximum. Science, 308, 1894-1898.

TyrRell, T. \& ZEEBE, R. E. 2004. History of carbonate ion concentration over the last 100 million years. Geochimica et Cosmochimica Acta, $\mathbf{6 8}$, 3521-3530.

UREY, H. C. 1947. The thermodynamic properties of isotopic substances. Journal of the Chemical Society, $562-581$.

Usdowski, E. \& HoEFs, J. 1993. Oxygen isotope exchange between carbonic acid, bicarbonate, carbonate, and water: a re-examination of the data of McCrea (1950) and an expression for the overall partitioning of oxygen isotopes between the carbonate species and water. Geochimica et Cosmochimica Acta, 57, 3815-3818.

Waelbroeck, C., Labeyrie, L., Michel, E., Duplessy, J. C., McManus, J. F., LAMBeck, K., BALbon, E. \& Labracherie, M. 2002. Sea-level and deep water temperature changes derived from benthic foraminifera isotopic records. Quaternary Science Review, 21, 295-305.

WEFER, G. \& BERGER, W. H. 1991. Isotope paleontology: growth and composition of extant calcareous species. Marine Geology, 100, 207-248.

WolF-GLADROW, D. A. \& RIEBESELL, U. 1997. Diffusion and reactions in the vicinity of plankton: a refined model for inorganic carbon transport. Marine Chemistry, 59, $17-34$.

Wolf-Gladrow, D. A., Bijma, J. \& Zeebe, R. E. 1999. Model simulation of the carbonate system in the microenvironment of symbiont bearing foraminifera. Marine Chemistry, 64, 181-198.

ZEEBE, R. E. 1999. An explanation of the effect of seawater carbonate concentration on foraminiferal oxygen isotopes. Geochimica et Cosmochimica Acta, 63 , 2001-2007.

ZeEbE, R. E. 2001. Seawater $p \mathrm{H}$ and isotopic paleotemperatures of Cretaceous oceans. Palaeogeography, Palaeoclimatology, Palaeoecology, 170, 49-57.

ZeEBE, R. E. 2005a. Stable boron isotope fractionation between dissolved $\mathrm{B}(\mathrm{OH})_{3}$ and $\mathrm{B}(\mathrm{OH})_{4}^{-}$. Geochimica et Cosmochimica Acta, 69, 2753-2766.

ZEEBE, R. E. $2005 b$. Large effect of hydration on ${ }^{18} \mathrm{O}$ fractionation between $\mathrm{H}_{2} \mathrm{O}$ and $\mathrm{CO}_{2}$ Implications for the $p \mathrm{H}$-carbonate- $\delta^{18} \mathrm{O}$ relationship and inferred climate changes. Geophysical Research Abstracts, 7 , 1607-7962.

ZeEbe, R. E. \& SAnyal, A. 2002. Comparison of two potential strategies of planktonic foraminifera for house building: $\mathrm{Mg}^{2+}$ or $\mathrm{H}^{+}$removal? Geochimica et Cosmochimica Acta, 66, 1159-1169.

Zeebe, R. E. \& Wolf-Gladrow, D. A. 2001. $\mathrm{CO}_{2}$ in Seawater: Equilibrium, Kinetics, Isotopes. Elsevier Oceanography Series, Amsterdam, 346.

Zeebe, R. E., Bijma, J. \& Wolf-Gladrow, D. A. 1999. A diffusion-reaction model of carbon isotope fractionation in foraminifera. Marine Chemistry, $\mathbf{6 4}$ $199-227$. 
Zeebe, R. E., SAnyal, A., ORtiz, J. D. \& Wolf-Gladrow, D. A. 2001. A theoretical, study of the kinetics of the boric acid - borate equilibrium in seawater. Marine Chemistry, 74, 113-124.

Zeebe, R. E., Wolf-Gladrow, D. A., Bijma, J. \& HöNISCH, B. 2003. Vital effects in planktonic foraminifera do not compromise the use of $\delta^{11} \mathrm{~B}$ as a paleo- $p \mathrm{H}$ indicator: evidence from modelling. Paleoceanography, 18, 1043.

ZhANG, J., QUAY, P. D. \& WilbuR, D. O. 1995. Carbon isotope fractionation during gas-water exchange and dissolution of $\mathrm{CO}_{2}$. Geochimica et Cosmochimica Acta, 59, 107-114. 